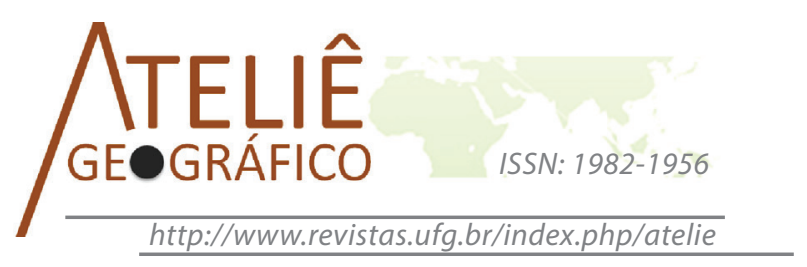

\title{
Agricultura urbana e gestão territorial em Recife/PE/Brasil: qual o lugar da agricultura urbana no planejamento da cidade?
}

\author{
Urban agriculture and territorial management in Recifel \\ PE/Brasil: what place of urban agriculture in planning \\ city?
}

\section{Agricultura urbana y gestión territorial en Recife/PE/ Brasil: ¿cuál es el lugar de la agricultura urbana en planificación de la ciudad?}

\author{
Rubio José Ferreira \\ Universidade Federal do Amapá \\ rubio.ferreira@pq.cnpq.br
}

Cláudio Jourge Moura de Castilho

Universidade Federal de Pernambuco

claudiocastilho44@gmail.com

\begin{abstract}
Resumo
Este texto tem como objetivo, sobretudo, dar visibilidade a um problema significativo para vários citadinos: o lugar da agricultura urbana e das pessoas diretamente envolvidas nesta atividade, no processo de planejamento urbano, a partir de exemplos ocorridos na cidade do Recife/Pernambuco/Brasil. Os principais resultados apontam que a agricultura urbana e os agricultores urbanos não são efetivamente considerados pelos técnicos das ações voltadas ao planejamento urbano de Recife. Isto, talvez, porque, a agricultura urbana se constitui de uma prática social utilizada por pessoas que pertencem a grupos sociais "hiperprecarizados" da economia urbana local. A ideia de planejamento territorial efetivo deve ser capaz de orientar políticas públicas que, a partir, também, da melhora das condições das atividades agrícolas na cidade, possam garantir a superação da perversidade das relações socioespaciais existentes em muitos lugares da cidade.

Palavras-chave: Agricultura Urbana; Gestão Territorial; Planejamento da Cidade.
\end{abstract}




\begin{abstract}
The aim of this text is expose an important problem with regard to urban men: the place of urban agriculture and the people direct involved in this activity. It demonstrated some steps in urban planning and the case study of Recife/ Pernambuco/Brazil (city/state/country). The main results show that the urban agriculture and urban farmers are in absence of the thoughts of Recife's planers. Maybe that happens because the urban agriculture is a social practice utilized by people from the "lowest layers" of society and in a marginal area in local urban economy. The idea of an effective territorial management is to guide public policies that promote better farming activities in city and assuring the diminution of poverty and the increase of human development in many places of the city.

Keywords: Urban Agriculture; Territorial Management; Planning City.
\end{abstract}

\begin{abstract}
Resumen
Este texto pretende, sobre todo, dar visibilidad a un problema importante para muchos habitantes de la ciudad: el lugar de la agricultura urbana y las personas directamente involucradas en esta actividad, en el proceso de planificación urbana, a partir de ejemplos que han ocurrido en las ciudades de Recife/Pernambuco/Brasil. Los principales resultados exponen que la agricultura urbana y los agricultores urbanos no son, en realidad, considerados por los técnicos de acciones centradas en la planificación urbana de Recife. Esto, tal vez, porque la agricultura urbana se constituye de una práctica social utilizada por personas que pertenecen a grupos sociales "hiperprecarizados" de la economía urbana local. La idea de una planificación territorial eficaz debe ser capaz de orientar las políticas públicas, encabezada, también, por la mejora de las condiciones de las actividades agrícolas en la ciudad, para que se pueda garantizar la superación de la perversidad de las relaciones socio-espaciales existentes en muchas partes de la ciudad.

Palabras clave: Agricultura urbana; Administración de Tierras; Planificación de la Ciudad.
\end{abstract}

\title{
Introdução
}

Este texto busca, sobretudo, dar visibilidade a um problema significativo para vários citadinos, isto é: o lugar da agricultura urbana, e, por extensão, das pessoas diretamente envolvidas nesta atividade, no processo de planejamento urbano, a partir de exemplos ocorridos no espaço intraurbano do município do Recife.

Até o momento atual, a agricultura urbana (AU) e os agricultores urbanos não foram, efetivamente, considerados pelos técnicos das ações voltadas ao planejamento urbano local, os quais, quando muito, têm procurado tratar a questão com programas e projetos de cunho mais assistencialista para atenuar tensões socioterritoriais. Isto, talvez, porque, além do fato da agricultura urbana não ter sido considerada como uma atividade especificamente urbana, ela constitui uma prática social utilizada por pessoas que pertencem a grupos sociais "hiperprecarizados" da economia urbana local.

1. Souza (2009, p.470) refere-se aos hiperprecarizados como "[...] uma população que, comumente, sempre viveu em circunstâncias de maior ou menor precariedade. [Noção que] ainda possui a vantagem adicional de permitir que se evite o problemático termo (e a problemática noção) 'lumpemproletariado', herdado do pensamento marxista tradicional $[\ldots] "$. 
Por outro lado, compreende-se o planejamento territorial - urbano no caso ora estudado - como um processo de elaboração e implementação de um conjunto de ações, pensadas e discutidas socialmente, não apenas tecnicamente, no sentido de realizar intervenções numa situação indesejada, construindo um território diferente, pelo menos livre da situação de fortes desigualdades e injustiças territoriais existentes.

Trata-se de defender uma ideia de planejamento que seja capaz de orientar políticas públicas que, a partir, também, da melhora das condições das atividades agrícolas na cidade, possam garantir a superação da perversidade das relações socioespaciais existentes em muitos lugares das nossas cidades.

Para aprofundar as discussões acerca do conceito de agricultura urbana, precisamos, portanto, estar atentos à dimensão territorial desta atividade humana, ou seja, ao uso econômico e político do espaço para a sua realização. Os artifícios econômicos e políticos contribuem, assim, para o processo de construção do território que é usado pelas próprias ações sociais, de maneira que é impossível entendê-lo em sua forma, estrutura e função, sem que se leve em conta as suas inter-relações processuais.

Na perspectiva acima esboçada, o texto foi estruturado de modo a, primeiramente, procurar entender, na história da cidade, o que é a AU para, em seguida, identificar as suas inter-relações com a elaboração de um planejamento territorial urbano numa perspectiva da construção de um território mais justo. É dessa maneira que pretendemos elucidar o papel da AU no planejamento da cidade.

\section{Agricultura urbana e suas inter-relações históricas com a cidade}

Um dos mais importantes aspectos utilizados para a definição dos espaços rurais tem sido a presença visível, em seu interior, de atividades agrícolas; o que ainda acontece, apesar do advento de processos inerentes à atual multifuncionalidade deste espaço geográfico. Contudo, é importante atentar para o fato de que a agricultura também se faz presente na cidade, nutrindo uma relação de conexidade, ou seja, de complementaridade, desde os primórdios do processo histórico da evolução urbana.

Portanto, atividades típicas do "mundo rural" sempre estiveram presentes em muitos espaços urbanos, tal como afirmado por Boukharaeva et al. (2005), influindo, às vezes, significativamente, no processo de produção das cidades. Sobre tal tema, Jacobs (1971) defendeu a tese de que a agricultura nasceu na cidade, afirmando que a origem da agricultura se deu na cidade. Para esta autora, a agricultura passou a ser produzida em espaços rurais apenas quando a cidade não tinha mais área disponível para cultivo. Mumford (1998) também mostrou que, nas últimas fases do neolítico, a partir da união de componentes páleo e neolíticos, teve-se como resultado uma revolução agrícola. Para este autor, nas aldeolas, há cerca de 15 mil anos atrás, já se vislumbrava o abastecimento doméstico por reprodução de mudas e criação de animais.

Atualmente, tanto a AU, quanto a periurbana e a rural são muito importantes, para as economias urbanas. É consenso, entre estudiosos, que os espaços urbanos e rurais estão 
cada dia mais inter-relacionados entre si. A AU é, assim, um dos elementos integradores do rural com o urbano por excelência, mesmo que aconteça mediante integração específica ao modo urbano de vida, engendrando complementaridades rural-urbanas.

Para entender a natureza e a funcionalidade da $\mathrm{AU}$, na atualidade, é preciso que atentemos, também, para as mudanças ocorridas no território, uma vez que esta instância social é, simultaneamente, meio e condição da realização social, tanto no âmbito do rural como no do urbano. Deste modo, as questões devem ser colocadas no sentido de entender o papel da AU não somente para o crescimento econômico, mas também para o desenvolvimento socioespacial das pessoas envolvidas.

\section{A complexidade conceitual e empírica da agricultura urbana}

Segundo um relatório do PNUD (1999), 800 milhões de pessoas, em todo o mundo, praticam agricultura urbana. No Brasil, em vários espaços urbanos, são encontradas experiências de AU, apoiadas ou não pelo Estado ou por ONG's. Por isso, o assunto tem tomado lugar nos debates dos estudiosos e gestores de políticas públicas na cidade. Alguns dos quais questionam a natureza da AU, bem como as formas de uso dos espaços por ela produzidos.

A AU, com suas engrenagens, permite a realização de fluxos que mostram, também, intensas relações complementares entre o espaço rural e a cidade, uma vez que a cidade não deixa de ser um lugar que assume funções diferentes a cada vez que a conjuntura muda. Nesse sentido, a cidade, refletindo a sociedade, como diz George (1993), torna-se o lugar em que o homem se utiliza das inúmeras disponibilidades espaciais nela existentes para desenvolver-se economicamente. A AU tem desempenhado papel fundamental neste processo, trazendo consigo a prática do cultivo per se e um conjunto de fatores sociais, econômicos e ambientais. Essa atividade assume características do modo de vida urbano, constituindo aí novos territórios e conceitos.

A AU é uma atividade humana a qual, por sua vez, possui também aspectos ambientais, econômicos e sociais, principalmente no que tange à sua relação com os princípios que se aproximam do que se defende como sustentabilidade, ou seja, desenvolvimento sustentável, como afirma Monteiro (2002). Contudo, convém acrescentar, a importância, também, das suas dimensões política e urbanística.

A dimensão política da $\mathrm{AU}$, ou seja, a integração da atividade às políticas urbanas é importante, na medida em que os aspectos institucionais interagem com o espaço e as suas atividades, permitindo ou entravando o seu desenvolvimento, através das suas ações. No que diz respeito à sua dimensão urbanística, observamos que tanto a forma urbana quanto a sua dinâmica processual interferem grandemente na agricultura produzida na cidade. Isto porque as condições ambientais são fatores importantes para o desenvolvimento da AU.

No que tange à sua dimensão social, podemos destacar diversos elementos, tais como: questões de gênero, inclusão social, geração de empregos, segurança alimentar, 
etc. Do ponto de vista da dimensão econômica, enfatizamos que se trata de um sistema de comercialização diferente do habitual e de um sistema produtivo que é profundamente integrado ao espaço urbano, podendo dar respostas a crises locais de abastecimento, tratando-se, neste sentido, de uma atividade que permite retorno econômico.

No que diz respeito, ainda, à dimensão ambiental, notamos que ela pode utilizar a biotecnologia, tecnologias inovadoras; e reaproveitar a água na agricultura, bem como os resíduos sólidos orgânicos, numa perspectiva da agricultura orgânica (sob princípios da agroecologia), integrando-se a novos contextos do espaço urbano contemporâneo.

Não podemos negligenciar nenhuma das dimensões acima mencionadas da AU, senão corremos o risco de entendê-la parcialmente, levando-nos a conclusões que não condizem com a realidade abordada.

Desta feita, as questões específicas da AU, citadas por Monteiro (2002), a saber: questões sociais (acesso à alimentação, saúde, segurança alimentar); econômicas (desemprego, geração e manutenção de empregos) e ambientais (poluição de águas, ar, solo, etc.), somadas às políticas (políticas públicas), estão intimamente imbricadas como totalidade complexa e não podem ser negligenciadas, quando se pretende entender as engrenagens da $\mathrm{AU}$ com o conjunto das suas funcionalidades no processo de produção dos espaços.

Ademais, embora apresente alguns aspectos semelhantes à prática de agricultura rural, a AU possui peculiaridades não apenas no que tange à sua localização - espaços urbanos - mas também, como lembra Mougeot (2000), principalmente porque ela acontece integrada intrinsecamente ao sistema econômico e ecológico urbano, remetendo-nos, mais uma vez, à complexidade da atividade no espaço urbano. Este autor ainda aponta seis fatores principais que devem ser observados na AU que, por sua vez, contribuem à sua conceituação e definição, a exemplo de: atividade econômica, localização, áreas utilizadas, sistema e escala de produção, e destinação de produtos.

Quando atentamos para o tipo de atividade econômica, consideramos que, na base produtiva da agricultura, tanto urbana quanto rural e periurbana, incluem-se também o processamento em alguns casos, a comercialização e interação entre estas fases. Quanto à localização, não podemos perder de vista a diferenciação da agricultura produzida nos espaços intra-urbanos daquela produzida nas áreas periurbanas, pelo menos no que tange a alguns aspectos, dentre os quais se destaca a escala de produção, que nas áreas periurbanas é maior do que nos espaços intra-urbanos. No que tange ao tipo de área utilizada para a produção, a AU pode ser realizada em áreas cedidas, arrendadas ou no próprio local da residência do agricultor, etc. Assim, podemos encontrar AU sendo produzida em diversos espaços tais como: margens de rodovias e avenidas, entornos de reservas florestais, manguezais, ilhas urbanas, margens de rios e reservatórios de água, dependências de residências, jardins, escolas, praças, associações de moradores, asilos, etc. As escalas de produção são reduzidas, em sua maioria, se comparadas às escalas de produção da agricultura rural e periurbana. Mas isto não quer dizer que esta redução seja incapaz de permitir sua sustentabilidade. Quanto aos sistemas de produção, estes 
são variados, definindo os tipos de produtos dos quais os mais comuns são os alimentos para consumo humano ou animal, bem como flores e plantas ornamentais. $\mathrm{Na}$ análise desta dimensão é importante estar atento para a sua integração, sobretudo, com o tipo de atividade econômica e com o tipo e a destinação dos produtos. Quanto ao tipo e à destinação desses produtos, a AU acha-se representada por necessidades do próprio autoconsumo ou por necessidades da comercialização ou as duas situações ao mesmo tempo. Portanto, esta dimensão acha-se agregada, sobretudo, ao sistema e à escala de produção e, consequentemente, ao tipo de área utilizada.

É importante ressaltar que, dos elementos citados anteriormente, o da localização parece claramente mais forte para a diferenciação da AU com relação à agricultura rural. Por este motivo, é preciso destacar "o princípio da integração ao sistema econômico e ecológico urbano" da atividade, para que, assim, se possa avançar numa definição mais sólida aobre AU (MOUGEOT, 2000).

Segundo Boukharaeva et al. (2005), corroborado por Mendonça et al. (2005), as funções da agricultura urbana residem basicamente em princípios de segurança alimentar, bem-estar (meio ambiente, saúde), identidade e laços de sociabilidade; reforçando a complexidade do tema, tal como estamos defendendo aqui. Pode-se então entendê-la como sendo uma atividade social de cultivo, produção e processamento de artigos alimentícios ou não alimentícios, praticada em espaços urbanos, utilizando e disponibilizando os recursos humanos e materiais do, para e por meio do espaço urbano.

Assim, é imprescindível que se leve em conta especificidades de cada lugar, bem como o tipo uma vez que o espaço geográfico não é homogêneo. Desta feita, é preciso que se faça distinção entre agricultura urbana e periurbana, pelo menos no que diz respeito aos aspectos conceituais, visto que se trata de espaços distintos (VALE, 2005). Do contrário, as ações desenvolvidas sobre e a partir dos espaços, ou seja, as medidas de políticas públicas para intervenção na AU poderão não apresentar os resultados esperados. Quanto à caracterização, para fins de gestão territorial da atividade, parece não haver nenhuma contradição em vincular as atividades agrícolas dos dois espaços, desde que estejam claras as suas diferenças e semelhanças e que, por sua vez, as ações sejam feitas levando em consideração estes aspectos.

Outro aspecto da AU que não pode ser negligenciado refere-se ao da sua dimensão familiar, manifestando-se, mais claramente, na medida em que se considera a integração das dimensões econômica, social e política da atividade. Isto porque a família desempenha papel importante nas relações sociais de produção da AU. Destarte, é preciso saber quais são os elementos da agricultura urbana que revelam a sua dimensão familiar, sob princípios da agricultura familiar.

\section{Lugares da agricultura urbana em Recife}

Por se tratar da capital do estado federado de Pernambuco e por se constituir no núcleo de uma região metropolitana (figura 01), Recife apresenta especificidades, mas, também, semelhanças com outros núcleos urbanos, principalmente da Região Nordeste 
do Brasil. Algumas das semelhanças dizem respeito aos diversos problemas sociais, econômicos, ambientais típicos das cidades grandes em regiões "subdesenvolvidas", como mostrou Melo (1978). Passadas quatro décadas da análise desenvolvida por este autor, e mediante a intensificação e consolidação do processo de globalização, não se extinguiram problemas antigos, herdados de um processo de excessiva concentração econômica, como mostra Araújo (2000a). Pelo contrário, diversos destes problemas persistem e/ou ressurgem, mas representados por outras formas.

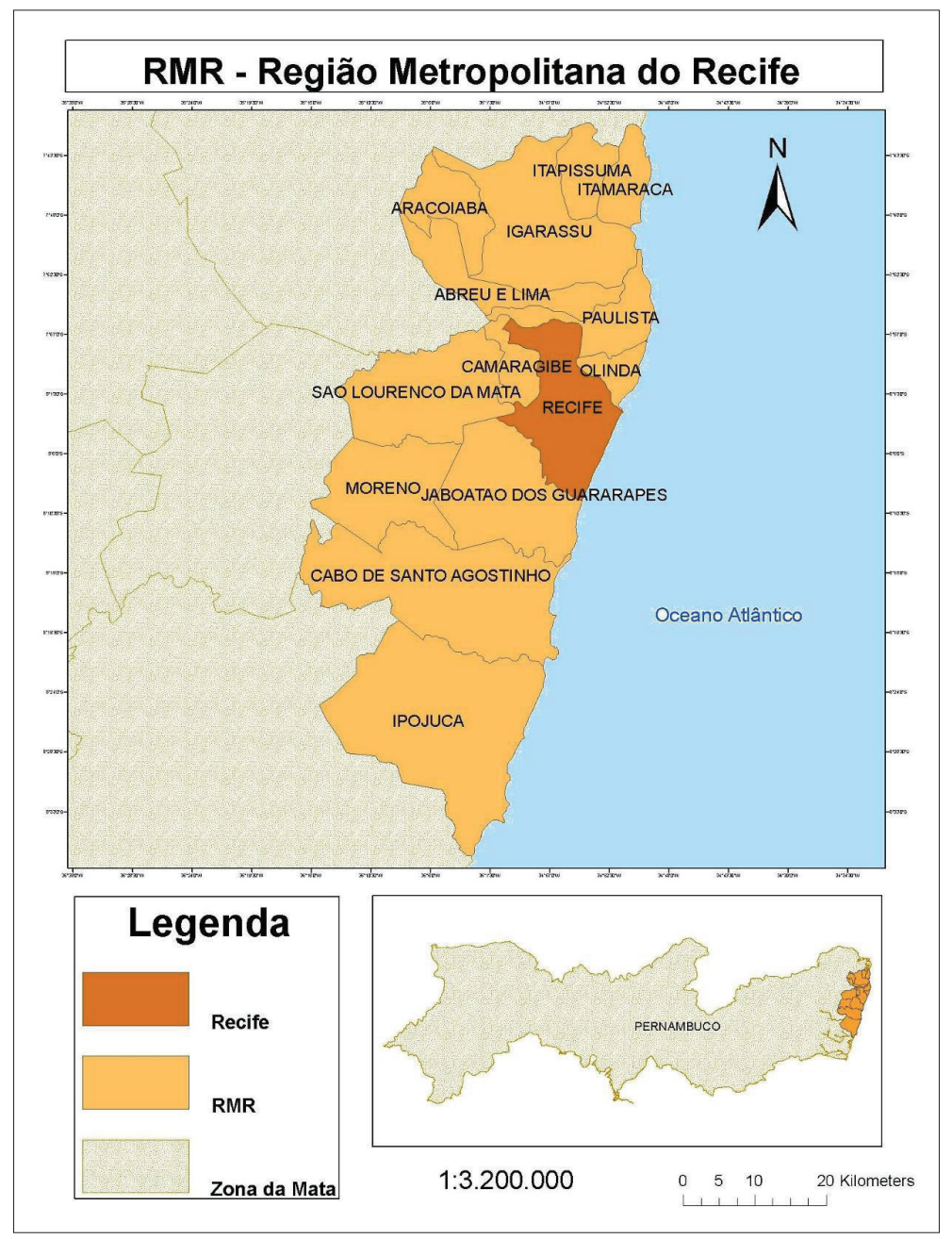

Figura 01 - Região Metropolitana do Recife, cidade do Recife, núcleo e capital do estado Elaborado pelos autores com base cartográfica do ZAPE (PERNAMBUCO, 2001). 
A agricultura, em Recife, tem lugar em áreas da cidade que são desprovidas de construções ou de outras formas de urbanização (parques, jardins, praças, margens de rodovias e de reservas florestais, etc.). As áreas ociosas são ocupadas de duas formas: ou por famílias que constroem casas formando as "favelas", ou para a produção de alguma atividade econômica, dentre as quais se destaca a agricultura.

Analisando a AU em Recife, foram identificadas 20 áreas com algum tipo desta atividade, como se pode ver no quadro 01. A distribuição espacial da AU em Recife está representada na figura 02 .

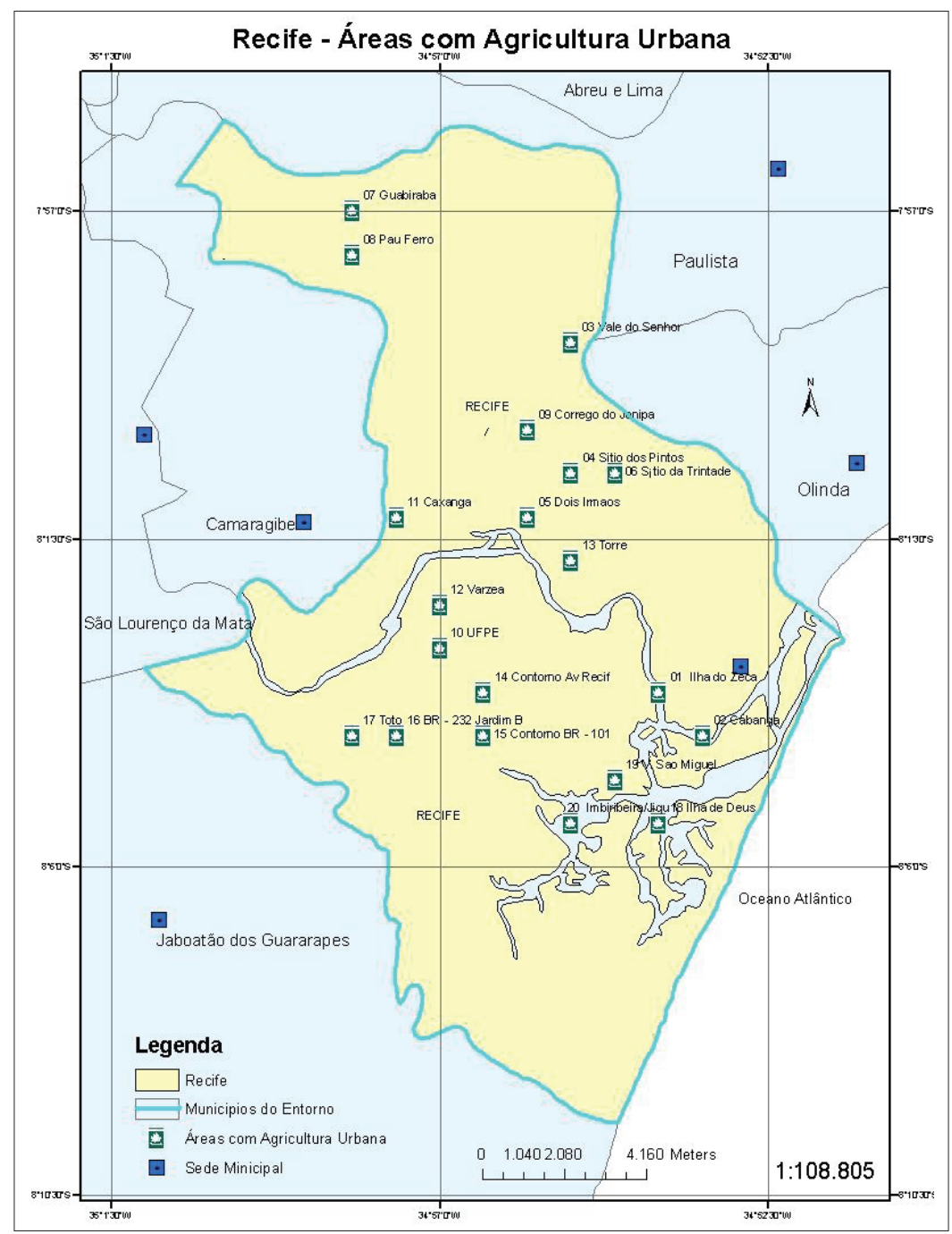

Figura 02 - Recife: distribuição espacial de áreas com agricultura urbana Elaborado pelos autores com base cartográfica do ZAPE (PERNAMBUCO, 2001). 
Quadro 01 - Recife: áreas com agricultura urbana e tipo de atividades

\begin{tabular}{|c|c|c|c|c|}
\hline \multicolumn{5}{|c|}{ Espaços da agricultura urbana em Recife, por tipo de atividades e classes de áreas } \\
\hline & Área & Bairro & Local & $\begin{array}{l}\text { Tipos de } \\
\text { Atividade } \\
\text { Predominante } \\
\end{array}$ \\
\hline 01 & Estuário do rio Capibaribe & $\begin{array}{l}\text { Ilha Joana } \\
\text { Bezerra }\end{array}$ & Ilha do Zeca & Carcinocultura \\
\hline 02 & Hortas comunitárias & Cabanga & Cabanga - Quartel & Carcinocultura \\
\hline 03 & Hortas comunitárias & Dois Unidos & Vale do Senhor & Agricultura \\
\hline 04 & Hortas comunitárias & Dois Irmãos & Sítio dos Pintos & Agricultura \\
\hline 05 & $\begin{array}{l}\text { Hortas urbana localizadas } \\
\text { próximo à reserva florestal; } \\
\text { Hortas comunitárias }\end{array}$ & Dois Irmãos & Dois Irmãos & Agricultura \\
\hline 06 & Hortas comunitárias & Casa Amarela & Sítio da Trindade (Sementeira) & Agricultura \\
\hline 07 & $\begin{array}{l}\text { Hortas urbana localizadas } \\
\text { próximo à reserva florestal; } \\
\text { Hortas comunitárias }\end{array}$ & Guabiraba & Bola na Rede/ Diversas & Agricultura \\
\hline 08 & $\begin{array}{l}\text { Hortas urbana localizadas } \\
\text { próximo à reserva florestal; } \\
\text { Hortas comunitárias }\end{array}$ & Pau Ferro & Pau Ferro & Agricultura \\
\hline 09 & $\begin{array}{l}\text { Hortas urbana localizadas } \\
\text { próximo à reserva florestal; } \\
\text { Hortas comunitárias }\end{array}$ & $\begin{array}{l}\text { Córrego do } \\
\text { Jenipapo }\end{array}$ & Centro Comunitário - CEMPO & Fitoterápicos \\
\hline 10 & & $\begin{array}{l}\text { Cidade } \\
\text { Universitária }\end{array}$ & UFPE & Agricultura \\
\hline 11 & $\begin{array}{l}\text { Hortas situadas próximo à } \\
\text { rodovias }\end{array}$ & Caxangá & Caxangá & Piscicultura \\
\hline 12 & Hortas comunitárias & Várzea & $\begin{array}{l}\text { Lar Fabiano de Cristo e Escola } \\
\text { Senador Novaes Filho }\end{array}$ & Agricultura \\
\hline 13 & Hortas comunitárias & Torre & $\begin{array}{l}\text { Centro de Ensino Popular e } \\
\text { Assistência Social (CEPAS) }\end{array}$ & Fitoterápicos \\
\hline 14 & $\begin{array}{l}\text { Hortas situadas próximo à } \\
\text { rodovias }\end{array}$ & Curado & Contorno Avenida Recife & Agricultura \\
\hline 15 & $\begin{array}{l}\text { Hortas situadas próximo à } \\
\text { rodovias }\end{array}$ & Curado & Contorno BR- 101 & Agricultura \\
\hline 16 & $\begin{array}{l}\text { Hortas situadas próximo } \\
\text { à rodovias; Hortas urbana } \\
\text { localizadas próximo à } \\
\text { reserva florestal }\end{array}$ & Curado & BR-232/Jardim Botânico & Agricultura \\
\hline 17 & $\begin{array}{l}\text { Hortas comunitárias; Hortas } \\
\text { urbana localizadas próximo } \\
\text { à reserva florestal; }\end{array}$ & Totó & CSU Bido Krause & Agricultura \\
\hline 18 & Estuário do rio Capibaribe & Imbiribeira & Ilha de Deus & Carcinocultura \\
\hline 19 & Estuário do rio Capibaribe & Imbiribeira & Vila São Miguel & Carcinocultura \\
\hline 20 & Estuário do rio Capibaribe & Imbiribeira & Imbiribeira/Jiquiá/Areias & Carcinocultura \\
\hline
\end{tabular}

Fonte: Trabalho de Campo (2005 a 2013). 
Das 20 áreas supramencionadas, podemos classificá-las em quatro níveis: conjunto de áreas situadas às margens de rodovias; hortas comunitárias apoiadas institucionalmente; hortas urbanas localizadas próximas às reservas florestais; e carcinocultura no estuário do rio Capibaribe. Somam-se ainda a AU produzida em quintais, às margens dos rios, etc. Vale destacar que uma mesma horta pode ser classificada em mais de um nível.

A agricultura urbana localizada às margens de rodovias - a questão do uso do solo urbano mediante a legislação e os zoneamentos para a agricultura tem sido um fator relevante no desenvolvimento da atividade, uma vez que se pode gerar tensões ou conflitos entre os próprios agricultores, entre os agricultores e o Estado e eventuais proprietários de áreas onde se pratica a atividade. Um exemplo de tensões entre agentes espaciais atrelados ao uso do espaço urbano para agricultura acontece em espaços do entorno do CEASA-Recife, como mostrou Ferreira; Castilho (2009 e 2013). Nessa classificação estão localizadas as áreas $n^{\circ} 14,15$ e 16, segundo o quadro 01 .

Ao que parece, as tensões ocorrem porque cada grupo de agentes tem interesses distintos sobre os referidos espaços. Os interesses variam conforme o tipo de agente socioespacial. O poder público ocupa-se em utilizar aqueles espaços para o fluxo de veículos, para tanto assegura por legislação própria que cabe ao Departamento Nacional de Infraestrutura de Transportes (DNIT) delimitar uma certa faixa de segurança (Art. 50 do Código de Trânsito Brasileiro). Por sua vez, o Centro de Abastecimento e Logística de Pernambuco (CEASA/PE), frequentemente ocupa espaços de sua área de expansão que nos últimos 30 anos são utilizados por agricultores urbanos. Ainda no que tange ao uso daqueles espaços pelo poder público, há preocupação da Companhia Hidroelétrica do São Francisco (CHESF) com a segurança das linhas de transmissão de energia. Por outro lado, com o crescimento dos bairros do entorno, algumas áreas antes ocupadas para a agricultura são destinadas à construção de unidades residenciais. Trata-se, portanto, de usos do espaço mediante as dimensões política, econômica e urbanística da agricultura urbana. Nesse contexto, não se pode esquecer de que a condição de vulnerabilidade em que se encontram os agricultores urbanos é o principal fundamento para a produção agrícola na cidade.

A densidade, comum ao espaço urbano, faz dele um lugar atrativo e, portanto, seu uso acontece mediante disputas como as que ocorrem no conjunto de terras localizadas próximas ao CEASA-Recife.

Das áreas com $\mathrm{AU}$ em Recife, aquela produzida às margens de reservas florestais apresentam a maior parte de elementos complementares entre o espaço rural e o urbano. Isso ocorre por diversos motivos, dentre os quais se acha o fato de que estes espaços constituem os que apresentam os menores índices de densidade em termos de urbanização. Tanto que, em alguns documentos e relatórios técnicos, tais espaços são classificados como semirrurais ou periurbanos.

Trata-se de áreas com predominância de mata que, em certos pontos, são seccionadas para ocupação por chácaras, pequenas propriedades, arruados de casas e, no 
caso das áreas localizadas nas proximidades do Horto de Dois Irmãos, a Universidade Federal Rural de Pernambuco (UFRPE). Por serem áreas de mata, à primeira vista, percebe-se que o grau de urbanização é bem menor do que nas áreas anteriormente destacadas, compreendendo Aldeia, em Camaragibe. Segundo Andrade (2006, p. 142), trata-se de áreas de antigos engenhos em que, ao longo dos anos, foram sendo construídos condomínios residenciais voltados para população de classe média e alta.

As características de Aldeia transbordam para Recife. A riqueza ecológica e a biodiversidade da Mata Atlântica, presentes na área, confere-lhe características plurifuncionais, típica de áreas periurbanas, como defende Vale (2005). Segundo a classificação mostrada no quadro 01, fazem parte deste grupo as áreas de número 03, 04, 05, 07, 08 e 17 .

A agricultura nos quintais das residências encontra-se pulverizada por toda a cidade. Pode-se encontrar AU tanto em bairros de baixo poder econômico, quanto de alto poder econômico. No caso dos bairros mais pobres, a agricultura produzida geralmente serve para autoconsumo e troca. Cultiva-se fitoterápicos e cria-se animais de pequeno porte (aves) e de grande porte (cavalos e porcos). Por outro lado, nos bairros mais ricos, a AU é produzida como jardinagem, ou em varandas de apartamentos; ambos voltados para autoconsumo, na perspectiva da alimentação livre de agrotóxicos. Esta agricultura não está mostrada na classificação do quadro 01 por ter sido difícil o seu mapeamento.

A agricultura urbana em hortas comunitárias - "são hortas urbanas, comunitárias, instaladas nas proximidades de "comunidades", nas quais os próprios moradores trabalham em coletividade" (SILVA, et al., 2006). Essas hortas, segundo a classificação mostrada no quadro 01 corresponde às áreas de $n^{\circ} 02,03,04,05,06,07$, $0809,12,13$ e 17.

A dinâmica espacial em cada um dos lugares supracitados é diferenciada, não apenas porque a produção é realizada de maneiras diferentes em cada lugar, mas também porque os grupos sociais envolvidos têm perfis socioeconômicos distintos e porque o uso do solo urbano, em cada um desses lugares, é diferenciado mediante legislações específicas do poder público municipal. O que repercute no esboço de especificidades dos lugares e da AU observados.

\section{Notas sobre o planejamento territorial diferente na cidade: qual o papel da agricultura urbana no planejamento territorial?}

A prática do planejamento requer do governo uma visão de médio prazo, ou seja, uma proposta norteadora de sua ação, cuja aceitação social pode ser negociada com as forças sociais nas fases democráticas, mas que pode ser imposta pela força, nos períodos de ditadura. (ARAÚJO, 2000b, p. 16). Diante disso, algumas questões tornamse insofismáveis nas preocupações de todos aqueles que, de alguma forma, ocupam-se da situação de injustiça social que assola os mais diversos espaços no mundo cada vez mais globalizado sob princípios neoliberais. Principalmente para aqueles que vêem no 
planejamento territorial uma importante ferramenta para a diminuição das desigualdades sociais, promovendo o real desenvolvimento urbano, numa perspectiva socioespacial.

Planejar é antes de tudo um exercício de preparação racional, para ações que visam concretizar um ideal, futuro desejado, como defende Santana (1990). Daí a necessidade de buscarmos identificar as bases desse planejamento, a fim de subsidiar as principais ações dos atores e agentes sociais locais, mediante a consideração da AU como ferramenta importante. O planejamento é, pois, "um processo de mobilização de forças e atores sociais para edificação de um estado desejado coletivo" (SANTANA, ibidem, p. 11), o grande desafio, do planejamento é, portanto, ir além do viável, ultrapassando o nível do possível e realizando o que julgamos, socialmente, não somente tecnicamente, ser ideal, ouvindo e dialogando com os principais interessados.

O planejamento territorial deve ser praticado como ação visando alcançar melhorias em termos de qualidade de vida e justiça social. Só assim é que poderemos nos aproximar da idéia de desenvolvimento socioespacial. Para o quê, é preciso que se leve em conta o tipo de espaço e as escalas em que e por meio das quais aquelas ações concretizar-se-ão, uma vez que o espaço não é apenas lócus, mas é também, concomitantemente, condição ao acontecer da vida social. Mas, pensamos em ações que, efetivamente, considerem a AU e, por sua vez, as pessoas a ela associadas.

Um planejamento territorial diferente, que contribua para o desenvolvimento socioespacial, perpassa por contraposições e resistências à manipulação do espaço pelo poder dominante, que, por sua vez, utiliza-se de estratégias político-econômicas racionalizadas de maneira a transformar os territórios em espaços sem vida(HAESBAERT, 2013). Nesse contexto, lembra Haesbaert que a base democrática permite o florescimento de territórios alternativos.

\section{A agricultura urbana no contexto do planejamento da cidade}

Algumas ferramentas da gestão urbana voltadas ao planejamento territorial são utilizadas no sentido de se regular a densidade e a forma da ocupação do espaço, ligadas a ações urbanísticas, aos zoneamentos de uso e ocupação do solo e aos índices ou parâmetros reguladores da densidade e forma de ocupação do espaço (SOUZA, 2006). Dependendo da maneira do uso (político, técnico, etc.) que se faz desses instrumentos, o território é modificado em sua estrutura, uma vez que o uso e a ocupação do solo urbano são regulamentados. A Lei Orgânica, reformada em 2007, o Plano Diretor, reestruturado em 2008 e os zoneamentos urbanos utilizados desde 1936 são as principais ferramentas de gestão que interferem na organização AU em Recife, uma vez que são estes instrumentos de gestão urbana que definem quais e como podem ser ocupados os espaços na cidade.

É preciso atentar para o fato de que esses instrumentos exercem influências sobre as atividades sociais, não podendo ser desconsideradas as articulações entre os diversos agentes políticos envolvidos (poder público, em suas diferentes esferas); senão corremos o risco de não compreender a realidade socioespacial que se pretende mudar. No que tange à $\mathrm{AU}$, mediante os citados instrumentos de gestão, os zoneamentos são 
de fundamental importância, visto que quando são identificados terrenos ociosos ou subutilizados na cidade, eles podem ser utilizados para a produção agrícola. No entanto, de acordo com a Lei Orgânica do Município, acima referida, não há zoneamento que identifique os lugares onde existe $\mathrm{AU}$, nem os potenciais para a realização desta atividade.

O descaso para com a AU impede, assim, seu desenvolvimento. Sequer se contabiliza o número exato de agricultores na cidade, bem como os espaços onde estas pessoas trabalham. Desse modo, como identificar suas reais necessidades? Enquanto a AU não for vista pelo poder público como uma atividade social e legítima, não se poderá promover inclusão social a partir desta atividade, tal como veiculado - como objetivos nos programas públicos, deixando-a a margem do planejamento territorial.

\section{Considerações finais: agricultura urbana e planejamento territorial com desenvolvimento socioespacial}

A AU, em Recife, não apresenta indícios de que tenha capacidade de gerar desenvolvimento socioespacial, até porque ela não promove mudança social per se na medida em que funciona apenas como amenizadora de problemas sociais cuja base reside na dinâmica das relações de produção mediante estruturas de poder que favorecem indiretamente apenas os interesses do capital. Mesmo que ela promova alguns benefícios - já que pode gerar renda, segurança alimentar; e fortalecer a solidariedade e a troca de informações (pelo menos no caso das hortas comunitárias) - de per se ela não promove mudança social efetiva. Uma evidência disto é que, dependendo do espaço em que a AU é praticada, não há melhora concreta em termos de qualidade de vida e justiça social para as pessoas envolvidas.

A AU poderá contribuir para um planejamento capaz de promover o desenvolvimento socioespacial na medida em que levar em conta os aspectos, ao mesmo tempo, sociais, econômicos, ambientais, urbanísticos e políticos em sua complexidade e totalidade, tal como visto no início deste texto. Quanto aos aspectos sociais, destacamos os seguintes: segurança alimentar - produção de alimentos frescos e saudáveis, bem como a produção de plantas medicinais; fortalecimento de laços de solidariedade produção coletiva (comunitária) ou familiar; troca de experiências e produtos; doação de produtos; fortalecimento da identidade e da autoestima dos agricultores.

No que diz respeito aos seus aspectos econômicos, apontamos os seguintes: geração de ocupação e renda; oportunidades de emprego; investimento inicial de recursos financeiros baixos; proximidade com relação ao mercado - menor custo da produção, menor concorrência; pouca exigência de qualificação profissional - uma evidência de que a AU é uma atividade socialmente pertinente, visto que pode abranger uma mãode-obra disponível e relativamente de baixos custos, justamente a dos grupos sociais hiperprecarizados.

No que concerne aos aspectos ambientais (ecológicos), destacamos os seguintes: reciclagem de material orgânico; reutilização da água; menor incidência de desgaste do solo; e redução de processos erosivos. Quanto aos aspectos urbanísticos, mencionamos 
os seguintes: ocupação de espaços ociosos - terrenos baldios, margens de viadutos, etc. E, por último, quanto aos aspectos políticos, convém lembrar os seguintes: ferramenta de inclusão social; ferramenta de proteção social; diminuição de desigualdades sociais; demanda social clara e objetiva; mão-de-obra disponível a custos baixos; e necessidade de poucos técnicos para desenvolvimento de projetos.

A agricultura urbana acontece em variadas situações as quais, por sua vez, são bastante heterogêneas no que tange ao uso dos recursos. Portanto, ela coexiste numa variedade de combinações contribuindo para a geração de renda, segurança alimentar e ecológica. Trata-se de combinações de diversidades de produtos, benefícios, situações, interesses e ambientes.

Por isso, antes de serem elaborados os programas e projetos de apoio à atividade em apreço, deve-se considerá-la de fato no planejamento territorial urbano levando-se em conta os cinco aspectos acima colocados em sua complexidade e totalidade. Com isso, constrói-se um conjunto de políticas fundamentais (de uso do solo, proteção social e ambiental) atreladas às necessidades reais das pessoas. $\mathrm{O}$ que somente um planejamento conseqüente poderá concretizar.

No que tange às políticas de uso do solo, não se pode esquecer que há intensa disputa pelo solo urbano. Portanto, a agricultura deve ser considerada, pelos planejadores, como uma forma legítima do uso do solo urbano, segundo Zeenw et al. (2000). Outro aspecto diz respeito ao da integração da AU nos zoneamentos desenvolvidos como ferramenta para o planejamento. Portanto, o planejamento deve ser específico com objetivos claros, contribuindo para o desenvolvimento da agricultura urbana a qual, por sua vez, contribuirá, num futuro, para o desenvolvimento socioespacial.

A partir da inclusão efetiva da AU no planejamento territorial urbano, devemos pensar em programas e projetos que estimulem a participação comunitária, a articulação organizada dos agentes (agricultores, ONG's e Estado) desde sua elaboração. As questões (sociais, políticas, econômicas e ecológicas) que permeiam a AU devem ser enfrentadas pelos agentes espaciais como um todo em um ambiente de contínuo diálogo entre os saberes e as práticas.

Em Recife, sabemos que algo está sendo feito, mas esse algo ainda é pouco diante da realidade de uma cidade fortemente marcada pelo desenvolvimento históricogeográfico desigual. Se não forem tomadas atitudes que busquem incluir, efetivamente, esta atividade no planejamento, perder-se-á outra oportunidade de, junto a tantas outras, promover inclusão social, autonomia e mudança de qualidade de vida, para um grupo considerável de citadinos.

Talvez apreender a AU no contexto da justiça ambiental e do ecologismo dos pobres (ALIER, 2014) ${ }^{2}$, seja um caminho importante para que a atividade social contribua significativamente para o desenvolvimento socioespacial.

2. Para Altier (2014, p. 357), os procedimentos de decisão no processo de governabilidade exigem contemplar "opiniões científicas e leigas, eventualmente contraditórias entre si, relevantes para diferentes escalas e distintos níveis de realidade". 


\section{Referências}

ALIER, Joan Martínez. O ecologismo dos pobres: conflitos ambientais e linguagem de valorização. São Paulo: Contexto, 2014.

ANDRADE, Ana Karina Nogueira. O Lugar em aldeia: Significados, valores, percepções e atitudes dos moradores dos condomínios residenciais de Aldeia, Camaragibe-PE. 2006. 299 f. Dissertação (Mestrado em Geografia) - UFPE, Recife, 2006.

ARAÚJO, Tânia Bacelar de. Ensaios sobre o desenvolvimento brasileiro: heranças e urgências. Rio de Janeiro: Revan: Fase, 2000a.

Descentralização das Políticas Públicas no Brasil: um destaque para a descentralização das políticas de apoio à Reforma Agrária. In: SOUZA, Aldemir do Vale; MOUTUNHO, Lúcia Maria Góes (Org.). Os desafios das políticas públicas diante da crescente importância do poder local. Recife: Sapiento, $2000 \mathrm{~b}$.

BOUKHARAEVA, Mansourovna Louiza; CHIANCA, Gustavo Kaurark; MARLOIE, Marcel; MACHADO, Altair Toledo; MACHADO, Cynthia Torres de. Agricultura Urbana como um Componente de Desenvolvimento Humano Sustentável: Brasil, França e Rússia. Cadernos de Ciência e Tecnologia, Brasília, v.22, p.413-424, maio/ago 2005.

FERREIRA, Rubio José; CASTILHO, Cláudio Jorge Moura de. Agricultura Urbana: Discutindo algumas de suas engrenagens para debater o tema sob a ótica da análise espacial. Revista de Geografia (Recife), v. 24, p. 07-24, 2009.

FERREIRA, Rubio José. Agricultura na cidade do Recife - PE: complementaridades rural-urbanas e dinâmica espacial. 2009. 159 f. Dissertação (Mestrado em Geografia) UFPE, Recife, 2009.

Agricultura urbana e periurbana e políticas públicas: contribuição à discussão do tema a partir de uma análise espacial em Recife e Vitória de Santo Antão/ PE. 2013. 231 f. Tese (Doutorado em Geografia) UFPE, Recife, 2013.

GEORGE, Pierre. Geografia econômica. São Paulo: Difel, 1976.

HAESBAERT. Rogério. Territórios alternativos. São Paulo: Contexto, 2013.

JACOBS, Jane. La economia de las ciudades. Barcelona: Edição 62 S/A, 1971.

LIMA, Audrey Oliveira. et al. PERNAMBUCO/SECRETARIA DE RECURSOS HÍDRICOS/Projetec - BRLi. Plano hidroambiental da bacia hidrográfica do rio Capibaribe: Tomo I - volume 03/03 / Projetos Técnicos. Recife, 2010.

MENDONÇA, M. M; MONTEIRO, D; SILVA, R. M. Agricultura Urbana: ensaio exploratório e pequeno mosaico de experiências. In: Agricultura na cidade - Coletânea de textos sobre as experiências desenvolvidas no âmbito do "Programa de Agricultura Urbana" da AST-PTA, na zona Oeste do município do Rio de Janeiro. Rio de Janeiro: AST-PTA, 2005.

MELO, Mário Lacerda de. Metropolização e subdesenvolvimento: o caso do Recife. Recife: UFPE, 1978. 
MONTEIRO, Ana Victória Vieira Martins. Agricultura Urbana e Peri-urbana: questões e perspectivas. Informações Econômicas, São Paulo, v.32, n.6, jun. 2002.

MOUGEOT, L.J.A. Agricultura Urbana: Conceito e Definição. International Development Research Centre (IDRC). Revista de Agricultura Urbana $n^{\circ}$ 05, 2000.

MUMFORD, Lewis. A Cidade na História: Suas Origens, Transformações e Perspectivas. São Paulo: Martins Fontes, 1998.

PNUD - Programa das Nações Unidas para o Desenvolvimento. Cultivando mejores ciudades. 1999. Disponível em: http://www.idrc.ca/es/ev-95297-201-1-DO_TOPIC. html Acesso em 20/02/2008.

SANTANA, Jorge. Notas introdutórias ao planejamento, Recife: [sine nonine], 1990. Mimeo.

SOUZA, Marcelo Lopes de. Mudar a cidade: uma introdução ao planejamento e à gestão urbanos. Rio de Janeiro: Bertrand Brasil, 2006.

. Práticas espaciais insurgentes em um mundo globalizado: da "revolução molecular" à política de escalas. In: MENDONÇA, Francisco, LOWEN-SAHR, Cicilian Luiza, SILVA, Márcia da (orgs.) Espaço e tempo. Complexidade e desafios do pensar e do fazer geográfico. Curitiba: Ademadan, 2009.

SILVA, Fernando Barreto Rodrigues et al. Zoneamento Agroecológico do Estado de Pernambuco - ZAPE. Recife: Embrapa Solos - UEP. Recife; Governo do Estado de Pernambuco (Secretaria de Produção Rural e Reforma Agrária), 2001. CD-ROM.

VALE, Ana Rute do. Definindo o Conceito e Descobrindo a Plurifuncionalidade do Espaço Periurbano. In: Congresso Brasileiro de Geógrafos, 6. 2005, Goiânia. Anais... Disponível em: HTTP://WWW.IGEO.UERJ.BR/VICBG-2004/EIXO3/E3_017.HTM Acesso em: 05 de junho de 2009.

ZEEUW, Henk; GÜNDEL, Sabine; WAIBEL, Hermann. A Integração da Agricultura nas Políticas Urbanas. Revista de Agricultura Urbana n ${ }^{\circ} 16$. 
Rubio José Ferreira

Graduado, Mestre e Doutor em Geografia pela Universidade Federal de

Pernambuco (UFPE). Atualmente é professor adjunto e pesquisador da

Universidade Federal do Amapá (UNIFAP) no Campus Binacional de Oiapoque, onde lidera o Grupo de Pesquisas Dinâmicas Espaciais, Território e Planejamento (GRUDEP).

UNIFAP - Campus Binacional. Rodovia BR 156, nº 3051. Bairro Universidade.

Oiapoque-AP.

E-mail: rubio.ferreira@pq.cnpq.br

Cláudio Jourge Moura de Castilho

Doutor em Geografia pela Université de Paris III (Sorbonne-Nouvelle) e Pós-

doutor na Università Ca Foscari di Venezia. Atualmente é Professor Associado da Universidade Federal de Pernambuco.

UFPE, Departamento de Ciências Geográficas. Av. Acadêmico Hélio Rarmos, $\mathrm{s} / \mathrm{n}$, Cidade Universitária. Recife-PE.

E-mail: claudiocastilho44@gmail.com

Recebido para publicação em maio de 2015

Aprovado para publicação em novembro de 2015 